\title{
Purism: Logic as the basis of morality
}

\author{
*Primus \\ primus@purity.org
}

This article introduces an a priori paradigm of beings and morality which distinguishes entities that are sought as ends from those that are sought as means to an end. The former entities, I offer, are the essence of personhood and are considered precious by observers possessing a logical system of valuation. The latter entities - those sought only as a means to an end - I term 'materials'. Materials are sought for their conditional value: important for achieving sought ends, they are not considered precious in and of themselves. A normative system for how this dichotomy of entities should interact is consequently derived and introduced. This paradigm has applicability for modern humanism and beyond. Assuming societal technological progression whereby human bodies and their surrounding infrastructures continue to evolve and integrate, the distinction between beings and their supporting materials, and a moral code for their interactions, will become ever more relevant.

Keywords: A priori; Beings; Desire; Logicality; Morality; Moral-Rationalism; Posthumanism; Purism.

\footnotetext{
*Primus holds a Bachelor of Psychology with Honors (Griffith) and a Masters of Policing, Intelligence and Counter Terrorism (Macquarie).
} 


\section{Purism: Logic as the basis of morality}

If one projects logic forward, the past becomes vastly more surreal than our prosaic future.

In this article I introduce an a priori definition of beings. Whilst I propose that this definition of personhood captures what is intuitively known to be the underlying value of humans, it also applies to non-human beings - including some, but not all, animals - and posthumans in whichever forms they may take. Importantly, the a priori nature of this definition allows for a moral paradigm to be logically ${ }^{1}$ and objectively ${ }^{2}$ deduced. This paradigm is derived from an examination of the intrinsically different value systems that logical observers place on the ends (final goals) that they seek, compared to the means (immediate and intermediate goals) used to achieve these ends. The term 'logical observer' is used herein to describe an agent with a sensical value system, which values ultimate goals (ends) above proximate goals (means), and apparently useful proximal goals above apparently less-useful proximate goals. Accordingly, a logical observer is capable of recognizing that:

a) entities sought solely as an end (i.e. for no higher purpose) will - or should (i.e. assuming the seeker of said end is logical) - have intrinsically greater value to the seeking entity than the respective means which are sought to achieve their sought end; and, that:

\footnotetext{
${ }^{1}$ By 'logically deduced' I mean that the answer is derived from the question, a priori, based on aspects of its definition. For example, if a human is defined as characteristics ' $x$,' ' $y$ ' and ' $z$,' we might deduce that each human ideally has the moral right to the resources that enable the fullest expression of $\mathrm{x}, \mathrm{y}$ and $\mathrm{z}$.

${ }^{2}$ By 'objectively deduced' I mean the nature of the answer itself is concretely (unambiguously) and universally knowable into the indefinite future, irrespective of whether or not the answer is theoretically accepted by observers.
} 
b) entities sought solely as a means should be sought (selected) for their specific properties which, of all the known means considered, would appear to most efficiently achieve the ends which are sought.

My argument progresses as follows: I observe that a want or a desire is, by definition, a state which is sought as an end. That is, desires are unconditionally sought, for the sake of being sought (as ends in themselves), as distinguished from those states which are conditionally sought to satisfy need (as a means to an end). I propose that all other aspects which are residual to the desires of beings (i.e. entities sought on the basis of need and entities which are unsought) should be considered as materials (resources), which either do, or could, serve as a means of realizing the states of beings. The category of materials includes, but is not limited to, the functional aspects of human bodies. I subsequently propose that our wants or desires, whether real or purely conceptual, form the essence of personhood. I do so noting that, in the context of any framework attempting to attribute status of personhood upon entities, it is logically implied that persons (entities which are sought to be protected by rights) are considered to be intrinsically more valuable than those entities which are not thought to deserve the status of personhood granted upon them. It is on the basis of this argument that the moral component of this paradigm is founded: logical observers should always consider any being (each sought as an end) to be more valuable than any material (each sought as a means).

I have titled this paradigm 'Purism'3 . This article consists of two parts. I firstly define beings through logically (I argue) contrasting them with their material surroundings. I secondly present a logically derived moral framework for this being-material dichotomy.

\footnotetext{
${ }^{3}$ The term 'Purism' is chosen to describe a consistent and culturally/politically-void moral paradigm which is untainted by "ideologies, worldviews and cultural assumptions" (Ramos, 2017, p.86).
} 


\section{Part One}

\section{Beings}

This paradigm recognizes two irreducible categories of value: 1. beings, and 2 . materials. Despite its conceptual 'duality,' this paradigm metaphysically subscribes to materialistic monism - the notion that all entities are reducible to a single material (for further details of this monism see Primus, 2019). I am not arguing for a metaphysical distinction within the being-material dichotomy, in contrast to mind-body Cartesian dualism. Rather, the distinction between beings and material is a conceptual categorization, made solely for societal moral purposes.

I define a being herein as states, attributed to a single mind, which are sought for an arbitrary or nil purpose. By 'state,' I simply mean any structure or action, conceptual or real. In less formal terms, a being is a collection of states, belonging to a mind, whose existence is wanted, as differentiated from states which are either needed (for other states to exist) or unsought (neither wanted nor needed). Notably, even if a being does not yet possess a realized version of their desires, or no longer possesses a realized version for reasons beyond their control (e.g. they cannot afford the resource to possess their desires, or they did possess them but they were stolen or damaged), their desire or 'want' is still considered to be a part of their being or 'self'. Desires, even if yet unrealized, can be considered to define their respective beings on the basis that, given a more-ideal set of conditions, their desires would (and perhaps will) be realized. In other words, any being's less-than-ideal state is owing to material inadequacy, not personal identity. All aspects of beings can therefore be considered to exist 'unconditionally' due to being sought for arbitrary, rather than logical (functional), purposes. The term 'unconditionally' denotes the potential for such states to be sought indefinitely, existing independently from external material conditions across time and space. This term does 
not indicate that such states necessarily will be sought indefinitely. For example, one could desire a white coat potentially in any place in the world and forever into the future, irrespective of how hot the ambient temperature is (or becomes). This is because a desire, by definition, is sought for arbitrary or nil purpose (e.g. the coat might be sought because 'it looks good'). If it is purely desired, the value of the coat is not dependent or influenced by changes in contemporary material conditions, such as weather, as it would be if it were sought for purely material purposes (e.g. as a means of keeping warm, or for its potential resale value).

The being-material dichotomy presented in this paradigm does not equate to a mindbody dichotomy. Rather, this paradigm classifies a mind as either a material or part of its being, depending, in each instance, on whether or not it desires itself. While many contemporary beings would consider their mind - the structure creating, and potentially changing, their abstract desires - as a part of themselves, a being does not need a mind (i.e. a mind need not desire itself) for its states of desire to be recognized accordingly as a being. Nor does a mind need to continue to exist post-creation of its desires for its desires to be recognized (indefinitely) as a being. The only inherent difference between a being with and without a mind which is still in existence is that the former possesses an ability to change its desires. This is so irrespective of whether said mind classifies itself as a being or a material. In other words, the only way a mind's desires can have their status of personhood revoked or forfeited is if their desiring mind ceases desiring them. I propose that there is no logical reason why any being should require the possession of a mind, nor why any desire should be invalidated on occasions that its desiring mind ceases to exist. Contemporary society recognizes the will of deceased persons, though this is usually limited to a distribution of material assets. It should appear intuitively logical that the desires of deceased persons should continue to be recognized indefinitely, and realized when and whilst there is the resource to do so. 
Furthermore, a being is neither required to be 'living,' nor possess 'agency' or intelligence, to be classified as a being according to this framework. A desire need not be a sensation or an experience; a desire at its most fundamental level is an expression of intent relating to an unconditional outcome. James Griffin views that at the core of personhood is "human dignity," comprised of "autonomy" and "liberty": "our capacity to reflect on, to choose, and to pursue what we ourselves decide is a good life" (Griffin, 2001, p.319). Griffin's $(2001,2008)$ view of 'agency' is inadequate as a definition of personhood. Again, there is no logical reason why the desire of a person who wants to exist forevermore in the form of a static state, without agency (e.g. as a marble statue), should not be entitled to the same materialsupport (resource) as a being who seeks to continually change their form (e.g. a living human being). I assert that it is not the notion of agency that is fundamental to personhood, but rather desires - including the desire to possess agency (or not).

Materials are defined negatively within this paradigm as entities which are not beings. Every state is categorized as a material, by default, unless sought for arbitrary or nil purpose. This framework therefore groups-together entities which actively serve beings on most occasions (e.g. human functional anatomy and technological infrastructure, barring illness or malfunction) with entities that either passively, or do not at all, serve beings. This category also includes those entities that may hinder the lives of beings (e.g. inanimate objects, viruses, weather phenomena). Everything other than beings - that which usually does serve beings and that which could serve beings - has been categorized together into the one group - 'material' - because these aspects are not sought as an end in themselves. If they are sought, they are so as a conditional means of achieving one's ends: the aspects that beings desire. In contrast to the unconditionally precious nature of the desires of beings, material states are, by their definition, considered to possess degrees of conditional value. At any moment, a material possesses a degree of importance to beings, in proportion to the degree, and for the duration, 
that it serves the intent of beings. A material in one condition (e.g. the use of 'fins' while scuba diving) may not be useful, that is, valuable, in another (e.g. the use of fins while running). This conditional value will be subsequently explored further as the notion of morality, in conjunction with the notion that all materials have responsibilities associated with the properties for which they are sought.

I propose that it would be arbitrary to distinguish human bodies within an enduring theory of beings and morality. Human beings need many other entities beyond their respective bodies to survive (e.g. the nutrients they consume, the atmosphere they breathe, the ground they walk on), and these aspects are rapidly changing and/or evolving (e.g. terra firma has been redesigned to propel us forward - escalators and travelators; autonomous vehicles drive us around).

At this juncture, I will clarify that beings are always theoretically distinguishable from their materials. Whilst any state (i.e. structure or action) can be sought for multiple purposes at any moment, logically, each part of each purpose assigned to any state cannot be both arbitrary and logical at the same moment. In other words, the terms 'arbitrary' and 'logical' are antonyms of each other and are thus mutually exclusive in any space at the same time. For example, a being may be appreciating the ambience of candlelight - an arbitrarily sought purpose and thus an end in itself - whilst its material body uses the same candlelight to write a work-related letter - a material purpose, serving a means to other purposes. In the instance of the latter, specific outcomes must be achieved through logical application of thought and action. The candlelight is a singular entity which is simultaneously sought for two purposes, both of which are sought in their own right and can thus exist in isolation from each other.

Whilst the delineation of people into separate components based on their purpose may seem both conceptually and practically awkward at first, it is morally vital, now and into the future. In the contemporary era it is important to draw a clear conceptual line between aesthetic 
expressions - those which should be protected from moral consequence under the auspice of freedom (e.g. free speech) - and expressions which necessarily carry moral consequence (e.g. right and wrong behavior). This distinction forms the basis of the argument in part two, whereby the states of beings are considered to be entirely protected from moral consequence, and the states (structures and actions) of all materials are viewed to possess moral value. The notion that beings are protected from moral consequence may appear counterintuitive at first, however, this notion will also be examined in part two.

Notably, the definition of beings as a cluster of arbitrary desires does not render human bodies as unimportant or unrelated to the beings they serve. Rather than simply viewing Purist beings as more-narrow versions of human beings, it is more accurate to view that this paradigm 'splits' human beings into two components - the being and material - based on the purpose of such components. Furthermore, this 'splitting' of human beings into being and material need not necessarily occur at the same moment in time - as it did in the candlelight example above - if the priority of a human being is clear (e.g. if the purpose of a human being is explicitly designated) in specific moments. In such instances, a human being may be considered to be acting overall in a capacity as a material or as a being, based on the primary purpose towards which they strive (or should strive) towards in any moment. A human who is on duty as a police officer would be primarily considered to be a material because their primary purpose at that moment is to serve the public. This is despite the officer also possessing desires (personhood) at the same moment; they may, for example, desire their appearance, their possessions and various activities that they plan to enjoy when not on duty. When the officer is off duty and doing something they enjoy, they would primarily be considered to be a being. This is despite their person concurrently being composed of multiple materials: their body's functional anatomy, knowledge and skills. Consequently, in this era - where beings and their human materials are bound together into a single body, whereby neither can be readily practically 
distinguished from the other - it is still possible to make a provisional delineation of being and their material based on the primary purpose of a human. We can and must distinguish between people primarily working (serving, as material resource) in society, and those that do not serve as a resource but simply exist as the (final) forms that they are. As will be discussed in part two, each possesses a different set of social/moral responsibilities.

Beyond this, the aforementioned distinction will become increasingly relevant into the intermediate and distant futures: posthuman eras, where the traditional human body has blurred with technological enhancements and automated technologies. ${ }^{4}$ In such futures, beings will presumably take many varied forms beyond the human body; it is vital that they are distinguished from material resources, lest they be consumed or discarded. ${ }^{5}$

\section{Part Two}

\section{Morality}

The distinction between beings and materials in a moral context, is arguably a logical distinction, not an arbitrary one. The notion of morality - what 'should' or "ought" to occur (or not occur), as opposed to the "is," (Hume, 1740) - necessarily invokes a prescription for an entity to either change or not change in order to exist within specific parameters. The aspects of a actor, object or society which are considered immoral are expected to change to become moral. The aspects that are considered moral must remain unchanged. Accordingly, the

\footnotetext{
${ }^{4}$ Most posthumanists adopt variations of this view (See, for example, Heylighen, 2002, 2015; Kurzweil, 2006; Chu, 2014; Last, 2014, 2015; Heylighen \& Lenartowicz, 2017).

${ }^{5}$ In part two I allude to a deeper future in which the materials of beings continue to be rendered such that they are more inconspicuous (e.g. concealed within the forms of beings in some instances and operating below their perceptual threshold in others) and more autonomous in their duty. I suggest that at this point, if materials are essentially homogenous in structure and endogenous to the forms of beings, the definition of beings presented herein may be the only way in which a person can be defined.
} 
proposed being-material distinction recognizes a fundamental difference between the purposes of entities. Some entities - specifically, materials: those entities which are perceived to be needed - are expected to not only exist, but to act, adapt, and improve, in accordance with specific parameters dictated by contemporary conditions. Materials are intuitively viewed by logical observers to possess responsibilities, to both their respective beings and to society in general. The proposed being-material distinction recognizes that the states of materials - and only materials - should be universally expected to operate within strict parameters, requiring them to either change or not change in any moment. Materials that are directly relied upon in any moment must not significantly change whilst fulfilling their function (e.g. atoms must not suddenly collapse in on themselves; a human heart must keep beating; a good government must keep governing). Yet, to better perform their functions into the future, all materials must continually, whether immediately or later, improve or be improved (e.g. atoms should eventually be replaced by materials which are more stable and autonomous; the structures of human hearts and good governments must continually become more decentralised, reliable and efficient). When a human being is at work, acting in a material capacity (for a purpose of need), a logical treatment requires them to be productive, efficient, and conform to specific regulations.

Conversely, other entities - specifically, beings: those entities which are wanted - need not change, nor assume specific parameters, nor even exist. These unconditionally-sought entities are ends themselves and thus possess no higher responsibilities and have no moral duty. For this reason, beings - whose states, by definition, are not needed to serve any higher purpose - are ideally able to assume any form. When a human being is acting in a capacity as a being, they can ideally assume any set of characteristics. This notion aligns with the well-worn concept of 'liberty' or 'freedom' (See Davis, 2016, Rawls, 2009, or any of the multiple theories and organizations espousing 'liberty' or 'freedom'). By ideally, it is recognized that there may 
need to be temporary and localized limits imposed by materials, which will prevent the realization of beings' desires from impacting others' ends. This would involve material (i.e. government) regulation of the times (when) and spaces (where) various states of beings can and cannot be expressed. This would not involve regulation of their natures (i.e. what types of being can or cannot exist). Ryan Davis, in his support of constitutivism, concludes that "we are rationally required to treat the liberty of persons as sacred" (Davis, 2016, p.28). The Purist would respond: 'the liberty of beings, if they desire such, yes; their materials, no'. Until the human being is theoretically dissected into being and material, the conceptual issues with discerning 'liberty' from 'anarchy' will continue to plague moral theorists, politicians, and the general public alike.

Therefore, unlike Levinasian ethics (Levinas, 1998), the recognition that a desire cannot be fully realized in any moment is not an indication that the desire itself is "too different" to be moral. This is so even if a specific state of desire may be too different from its contemporary societal norms to allow it to be peacefully realized at any moment. Rather, it is an indication that contemporary materials are too inadequate in a particular moment to be considered moral (acceptable to society).

The aforementioned reasoning makes a small but important adjustment to Emmanuel Kant's (1785) notion that human beings in their entirety should be treated as (precious) ends. Rather, it is the aspects that each human respectively seeks as an end - whether these states are real or purely conceptual - that is the extent of their preciousness. In other words, it is not that human beings should be treated as ends, their aspects which meet the definitional criteria of beings are ends. Desires are ends, by definition, whether recognized as such by observers or not.

In addition to the notion that not all aspects of humans should be considered precious, the reasoning within this paradigm confirms the intuition of many (for example Kelly, 2014; 
Schwartz, 2014; Riddle, 2014; Oriel, 2014; Jürgens, 2014; Davis, 2014; Cordeiro, 2003) that there are entities beyond human beings which should be considered precious. This framework recognizes the preciousness of the wants of animals, where applicable, as differentiated from their instinctual strivings (to satisfy need). Whether or not these rights could be realistically granted in contemporary conditions is another matter, depending on the material ability to know and realize these desires. The Purist definition of beings also allows for an a priori provision of rights to yet-unencountered beings (e.g. extra-terrestrial and/or those existing with synthetic bodies; for examples, see Dvorsky, 2014; Cordeiro, 2003). Finally, this framework recognizes that static forms of beings (e.g. a building with historic or personal value) may be considered just as precious or more precious as living beings, depending on the strength by which such desires are sought.

I will now examine the unconditional value (preciousness) of desire and the conditional value (importance) of materials in the context of a moral ${ }^{6}$ paradigm. The states of beings are necessarily viewed as amoral - they are neither right nor wrong. I argue that 'right' and 'wrong' - the "ought," as opposed to the "is," (Hume, 1740) - exists only within material conditions, and in all material conditions.

\section{The amorality of beings}

It may initially seem counterintuitive to consider that any state of any being is necessarily amoral - neither 'good' nor 'bad' - especially in relation to intent for violence towards or oppression of other beings. The summary justification to this concern is that the

\footnotetext{
${ }^{6}$ I use the term 'moral' rather than 'ethical' due to the unconditional, a priori nature of this paradigm: the 'rules' presented within thus do not change in accordance with conditional variables, such as cultural norms (MacIntyre, 2006).
} 
states of beings themselves, by their definition, do not necessarily affect others, and if they do, their effects are subjective ${ }^{7}$; what may be enjoyable for one being may be frustrating or even nightmarish for another. And where there is incongruence between desires (e.g. being A wants to do $\mathrm{X}$ to or with being $\mathrm{B}$, but being $\mathrm{B}$ either explicitly does not want $\mathrm{X}$, or $\mathrm{X}$ is incongruent with the desires of B), it is the materials realizing the desires of beings in any moment which are morally accountable, not the desires themselves. More specifically, the occurrence of immorality, such as the violation of beings against their intent, is always due to a failure of material(s) to limit or vary the realization of desire prior to the point in which it interferes with the realization of other beings' desire; the desires themselves are not 'wrong,' but rather spatially incompatible in that moment of time. For example, assume a being, B, views being A walking with their white coat, and, for whatever arbitrary reason (e.g. for enjoyment, or because they subjectively find the coat to be 'distasteful'), intends to cover A's coat in red paint. If B is able to splash A's actual coat contrary to A's intent, it is the materials which both allowed and enacted this - namely, the human body of B, its sub-materials (the muscles and central nervous system), and technically even the passive nature of the materials within the red paint itself - which are morally accountable. The argument for viewing that inanimate objects can possess values of (im)morality will be discussed subsequently.

We can conceive conditions whereby even desires which significantly deviate from contemporary social norms could be realized within limits that do not contradict the desires or material functioning across society. This may mean that some desires are never fully realized (e.g. limited to remain in their respective minds). In either case, the onus is on moral absolutists to argue why any desire in such condition (isolation) should be considered 'immoral' or 'unethical'. To the contrary, this paradigm proposes that it would be arbitrary, and actually morally wrong, for one to assert that any desire - a state which, by its definition, neither

\footnotetext{
${ }^{7}$ This serves as my definition of metaethics: those states which necessarily and objectively affect other states.
} 
necessarily nor objectively affects others - should be universally prohibited or altered. Whilst it is convenient to blame the source of B's act in the example above - being B's intent to splash A with red paint - there is nothing inherently right or wrong about B's intent itself. In conditions where materials actively prevent the realization of intent that would violate the peace of others, there is no logical reason why B should not be able to possess the intent to splash paint on another. Such intent is a part of the identity of being B, just as A's white coat forms part (or all) of their identity. B's intent, as per any intent, is harmless in its own right and can be peacefully expressed if its realization is logically limited or varied (the desire itself should not be limited or varied). The peaceful realization of B's desire may be expressed in various forms, depending on the material resource available (e.g. the degree of societal technology). At any moment it may range from thoughts/fantasies within the mind of B, to a play/movie/(re-)enactment, to a simulation occurrence where B splashes a replica of A whilst believing it is the form of A. Furthermore, there is always the possibility that A (or another being) may want to be splashed with paint in future occasions.

The notion that beings (desires) should be considered amoral - void of (im)moral value - is reinforced by the nature of what I will assert does constitute (im)moral value: I will subsequently argue that logical observers intuitively sense that morality directly relates to the probable efficiency of a material achieving a logically prioritized end (i.e. a moral material is one which pursues logical ends via logical means). If this is true, beings do not qualify to possess a moral value by their definition; they are specifically sought for an arbitrary purpose (or nil purpose), not a logical purpose. The absence or arbitrariness of the purpose for which they are sought ensures that their states are neither right nor wrong, that is, neither efficient nor inefficient at achieving an end. Rather, beings are ends themselves - even if their states are 
sought as means to other ends. ${ }^{8}$ On the basis of their arbitrariness of purpose, the value of any being can only be evaluated subjectively by other beings, if evaluated by other beings at all. Desire which appears repugnant to one being may be welcomed by another. A being's desire to wear a white coat for arbitrary purpose is neither right or wrong, moral nor immoral; it may however be perceived and judged by the subjective standards of other beings (e.g. 'ugly' or 'attractive').

Let us now consider if the action sought by being B in the above example - to splash being A with red paint - were sought by B for a material purpose, rather than being desired as an end in itself. As such, the same act would not, by definition, be sought by actor $^{9} \mathrm{~B}$ for arbitrary or nil purpose (e.g. enjoyment), but rather, the act would occur either as an (unsought) accident, or as a perceived means of rendering the world in the image of how the actor (B) believes it should function (i.e. a political action). Let us assume that it is not an accident and that actor B believes that they need to splash being A with paint (as a perceived means to some other purpose). For example, B is an activist, protesting against A's white coat, which they perceived to be constructed from animal fur. In this instance, both the thought and action of splashing A with paint would each serve a material purpose and B would be acting overall in a material capacity, or specifically, the components of B which embody these purposes could be considered to be materials. In the spirit of Levinasian ethics - where merely existing has an ethical value - both the act and the plan to act for such a purpose can be considered to possess a moral value because each necessarily and objectively affects other states. There are only a finite number of materials at any moment, and a fewer number which are capable of actively

\footnotetext{
${ }^{8}$ For example, if player ' $\mathrm{P}$ ' on a sporting team is using his teammate, player 'Q,' merely as a means of blocking the path of an opposing team member so that they, $\mathrm{P}$, themselves can score a goal, then both $\mathrm{P}$ and $\mathrm{Q}$ are both existing as ends providing they both desire to play the sport, including if $\mathrm{Q}$ does not approve of being used by $\mathrm{P}$ in such manner.

${ }^{9}$ Note that ' $\mathrm{B}$ ' is now referred to as an 'actor,' rather than a being or a person, on the basis that the latter, by definition, cannot possess material purposes.
} 
working to realize the desires of beings. When someone possesses beliefs and/or actions of one nature, they are reducing their capacity to concurrently believe and/or act in another capacity; there is a finite quantity of beliefs that any actor can hold, and finite actions that they can take, in any moment - especially if the actor refuses to hold incongruent beliefs and/or take actions which are incongruent to their beliefs. Accordingly, because material thoughts and actions are a finite resource - a means of realizing desire - the nature of each material thought and action affects each member of society, not just those directly involved (in this example, actors A and B). Society benefits when material thoughts and actions are appropriate and it suffers when they are inappropriate. I will explore the concept of '(in)appropriate' further, yet for now the reader can recognize the objective and necessary affect that each (finite) material action or thought has on society: each either will or will not maximize the benefit and good within society. If a material thought or action of covering another in paint is inappropriate (wrong) then no one benefits. In this example, one actor (A) gets covered in paint against their will, which will require societal resource to rectify ${ }^{10}$, and the actor completing the act (B) gets no personal gain (noting that they did not want to complete their material act). Society misses out on the benefits of a 'right' action, as the time and energy used to think and act in this instance could have been directed so that beings A, B, C or D could have had their desires realized; society also pays for the consequences of the wrong action, expressed as the material cost to rectify the condition.

I will conclude this section by reiterating what is perhaps the most counter-intuitive aspect of this proposed paradigm. Irrespective of the nature of each desire, in any condition, it is the materials which realize (i.e. support and enact) or fail to realize (i.e. limit or vary) these desires that are morally accountable. All desires are amoral: neither right, nor wrong.

\footnotetext{
${ }^{10}$ By 'rectify' I mean restore (in this example: clean) being A to their desired form and attend to the inadequate nature of the material of being B (e.g. punishment, education), such that a similar event does not occur again.
} 


\section{Material (im)morality}

I have offered that materials (e.g. atoms, molecules, government, human bodies, and other needed infrastructures) are important to the degree, and for the duration, that they each satisfy the needs of beings. Because material acts are sought as means to an end, all materials can be viewed to possess objective requirements that they must satisfy at any moment. These requirements relate to both the purpose that a material is trying to achieve, and the means that they use to achieve it. I argue that logical observers intuitively demand that materials must employ logical means towards realizing a logical purpose. It is this requirement (duty or responsibility) - for materials to act logically, to possess logicality - that is viewed intuitively by logical observers as the notion of 'morality': what should occur in any given condition.

There is no universal definition of 'logic'. Rather, there are many various types (e.g. modal, mathematical, philosophical; Ayer, 1946; Maddy, 2012; Putnam, 1972, Dauben, 1990; Carnielli \& Coniglio, 2016, Aristotle's Metaphysics). Some (e.g. Schick, 1966; Coons, 1987) have argued that the various types of logic are broadly connected by the notion of consistency. I (Primus, 2019) view the two terms, logicality and consistency, as synonyms. The elusiveness of universal or widely accepted definitions of these concepts is largely inconsequential to the success of this paradigm. I use the terms logicality and consistency ${ }^{11}$ synonymistically in this paradigm to describe the essence of objectivity: a natural, default state that exists when arbitrariness and subjectivity is absent. In the spirit of Coons (1987) and Schick's (1966) indirect definition of consistency, I negatively define logicality (consistency) - the property of being logical (consistent) - as the absence of arbitrary difference (i.e. variance and/or limitation) within a condition.

\footnotetext{
${ }^{11}$ I further use the term 'purity' as a more succinct and eloquent synonym for these terms.
} 
I will now briefly detail the requirements of a logical material purpose and means, noting that they are characterized by an absence of arbitrariness.

For the purposes of this article, a purpose is defined as the most distal state (i.e. endstate) towards which a material strives. A logical material (e.g. government or human body) recognizes that the unconditionally-sought nature of beings is intrinsically more valuable than the conditionally-sought nature of materials, and strives to realize the states of beings without arbitrary limitation or variation of their desired state(s). In other words, it should seem intuitively logical that states of greater definition should be prioritized beyond states of lesser definition: states which are temporarily sought as a means to more-defined states, if sought at all. Similarly, it should seem intuitively illogical (arbitrary) if any material were to strive to limit or vary the realizations of the desires of beings as their final purpose, that is, for the sake of doing so in the absence of a higher, logical reason to do so.

I argue that a material (e.g. government or human body) is immoral to the degree that it arbitrarily limits or varies the lives of beings, and specifically, it is immoral in purpose to the degree that it strives to do so. A government possessing an immoral purpose, for example, may strive to universally and permanently prevent their citizens from wearing brightly-colored clothing, for arbitrary reason (e.g. because "they say so" or because of a "sacred" text). This is not to be conflated with conditions where a moral government needs to conditionally (locally and temporarily) prevent some of its citizens (e.g. military members) from wearing brightlycolored clothing as a logical means of achieving its purposes (e.g. due to the need for uniformity or to be camouflaged).

In striving to serve the ideals of beings, therefore, the realization of beings' desires may need to be conditionally (locally ${ }^{12}$ and temporarily) limited or varied for logical reasons. These

\footnotetext{
${ }^{12}$ The term 'locally' here means restricted to a limited space, e.g. a government that limits one citizen from driving, or limits driving in a specific area, rather than completely banning driving across society.
} 
logical reasons may be purpose-related, that is, relating to the final outcome that a material is striving to achieve (e.g. if the wants of being A conflict with the wants of being B, it is logical that the realization of A's wants should be limited prior to the point that they interfere with B). They may also be means-related (e.g. if there is insufficient resource to realize the wants of all beings at any moment, it is logical that the realization of the wants of beings must be limited).

In addition to striving to realize the states of beings without arbitrarily limitation or variation, I propose that a material pursuing a logical purpose will logically prioritize its service to beings (in conditions where prioritization is needed). If prioritization between or within beings is required to occur (e.g. due to a shortage of resource or where beings' desires are incompatible), a logical material will prioritize resource to the greater strength of desire. For the purposes of this article, the strength by which a state is desired or wanted is a product of the intensity and the duration of a desire. All other factors being equal, I offer that it would be illogical for a material (e.g. government) to give a person (being) something they do not want, especially when there is another person who does want what is being offered. This same principle is extended to degrees of desire when multiple people desire the same entity: all other factors being equal, it would be logical to give the entity to the person who has wanted, and likely will continue to want, the entity for the greatest intensity, for the longest duration of time. In other words, for the same reason that the unconditionally-sought states of beings should be viewed as being intrinsically more valuable than materials, logical observers should recognize that states of desire which are sought with a greater degree of desire (in space), over a greater duration (in time), exist with greater (metaphysical) definition across time and space.

Not only should it seem more logical in a prescriptive sense to prioritize states which are more defined across space and times, it should seem more logically possible. A sought state which is relatively undefined across space (e.g. desire for a 'square-circle') is difficult to realize 
in the absence of a clearly defined purpose to strive towards (e.g. desire for a 'square'). In attempting to realize the former, a material must decipher whether a 'square-circle' is a square with rounded vertices or a square and a circle integrated together in some other way. A state which is relatively undefined across time (e.g. a 'square changing into a circle changing into a triangle changing into...') presents similar difficulties for materials attempting to realize said state(s). Factors affecting the metaphysical definition by which any desire exists shall be explored in subsequent articles.

For the purposes of this article, a means is defined as the immediate and intermediate states that an entity assumes to achieve a purpose. A logical material will continually assume states which will probably most efficiently achieve its purpose. A material state which will probably most efficiently achieve a purpose is necessarily void of arbitrary variance or limitation within its means. Any such arbitrariness would produce inefficiency.

Logicality of means is partly the function of the action or inaction taken by a material in any moment. Accordingly, even a government or human body which has a logical purpose (i.e. they strive to logically prioritize realization of the desires of beings without arbitrary limitation or variation) can act immorally (that is, illogically) "towards" their purpose on account of their means. Such a body would be acting with a degree of immorality to the extent that their actions towards their purpose would probably be arbitrary, and thus a waste of resource.

Logicality of means is also the function of a material's (organizational) structure. Whilst the forms of future beings are difficult to predict, I assert that we can predict the structural evolution of societal material as it undergoes logical, technological progression to be rendered more efficient at achieving its (need-based) purposes. I argue that to improve at performing their purposes in accordance with the expectation of logical observers, the logical 
path of materials is to perpetually become more adaptive (i.e. active ${ }^{13}$ and variable) in function, smaller in size, more plentiful in quantity, and more simplified, stable and homogenous in structure (i.e. composed of fewer levels of sub-materials ${ }^{14}$ and becoming ever more independent ${ }^{15}$ from, but interoperable with, each other, in terms of their structural design). Due to space restrictions, and perhaps the sheer simplicity and obviousness of the assertion itself, I will not thoroughly defend here why I assert that it is logical that this, and only this, structural reform leads to greater efficiency. As an example of this self-evidence, it should appear intuitively logical that: multiple bodies can produce more work than a single body of the same nature; more bodies can operate in any one space if they are smaller; bodies, even if serving a collective purpose, should not be structurally entangled with, or dependent on, each other where possible, allowing them to change their structure and location in accordance with revised purposes and dynamically changing conditions.

The natural design of human hearts, for example - categorized as materials, because they are needed (a means to a higher purpose) - logically should not remain as they currently are: singular to each human body, passive in nature, and relatively complex (Hill, 2020) and unstable in structure. Contemporary human hearts cannot sense blood pressure and adjust their output accordingly. Despite being singular in function, they are comprised of many sub-

\footnotetext{
${ }^{13}$ By 'active' I mean autonomous (self-initiating) in terms of its service to beings and in its own technological advancement.

${ }^{14}$ For example, human bodies are relatively complex and unstable because they are composed of many 'levels' of sub-materials which appear not to have been purposely designed for human use (based on their relative inefficiency, unreliability and passiveness to human purposes); human organs are composed of cells, cells are composed of molecules, molecules are composed of atoms, atoms are composed of sub-atomic particles, and so on...

15 'Independence' describes the need for materials to become increasingly less structurally reliant on, and entangled and shared with, each other; this is a logical requirement for increasing material ability to efficiently serve the (often divergent) intent of beings. Independence allows materials to work together with interoperability: collectively working to achieve a singular purpose, without structural dependency on each other.
} 
materials (e.g. arteries, valves, cells) which are each prone to malfunction, and they have no self-reboot backup system should they suddenly cease pumping. Each heart could also be continually redesigned to pump more efficiently. If we follow a logical path of progression, for the duration that blood is needed to travel around human bodies, the future cardiovascular system of humans should be continually redesigned so that they are ever-more decentralized; there should be multiple hearts throughout the body (first there was one, then perhaps two, then five, then eventually ten, then 100 - each becoming smaller as more are added); hearts should also become ever more active, automatically sensing how much blood they should pump and where; they will be more efficient (i.e. pump more blood using less energy); they will be moresimply designed (i.e. composed of fewer layers of sub-materials and working-components, e.g. less valves and chambers) and thus will be less prone to sudden stoppage, and will be able to restart or self-repair themselves if they do suddenly malfunction. Beyond this, we can anticipate that there will exist a time when hearts are unnecessary because blood cells themselves can be redesigned to actively propel themselves around human bodies to where they are most needed (whilst in communication with each other and their respective brain).

The moral requirement for logicality within the states of materials necessitates that beings and materials exist and operate in concerted, yet parallel, realms. Materials must be structured such that the nature of beings' intent - especially including their culture, ideology and political views - is unable to interfere with the logicality (impartiality/apoliticality) of their operation, and vice versa. Materials - with the exception of a respective beings' mind - must not be able to change or interfere with the nature of a beings' intent. The need for parallelization of beings and material is already intuitively recognized by modern societies with the contemporary notion of the need for separation of 'church' and 'State'. This concept, extended to its fullest conclusion, entails the need for separation of politics (i.e. opinion, subjectivity, 
culture) from the required apoliticality (logicality, consistency) of materials. This, of course, necessitates that governments be properly structured with sufficient transparency to identify, rectify and safeguard against not just isolated instances of corruption, but systemic occurrences of political action; every government policy and action should be logically justifiable.

\section{Provisional and absolute morality}

I introduce the concepts of provisional and absolute morality in recognition of the aforementioned expectation for states of material to respectively act within specific parameters in the immediate moment and yet also eventually change (or be changed) to better perform their functions in future moments. Accordingly, the above examples, of government policy not arbitrarily limiting citizens, of government and human bodies not wasting resources, each concern what I describe as 'provisional morality'. Provisional morality encompasses the states that active (autonomous) materials (e.g. human and government bodies) should immediately assume within any given condition to render said condition provisionally or relatively moral. That is, the condition is still recognized as being imperfect (i.e. it is less than an absolutely moral, ideal world) though logical observers would view that the condition is as moral as possible considering the resources available within said condition. Put more simply, ‘(provisional) morality' describes a disposition which can and should be adopted by a material entity possessing agency in any moment to produce the most moral outcome possible, given their limited means. Because the term 'provisional morality' aligns with the general concept of morality (i.e. what an agent must do or not do in any moment) it can be used synonymously with the term 'morality' in general discourse.

Concurrent to the need for autonomous material entities to act morally in any given condition, this paradigm recognizes that it is the presence of an imperfect world in the first 
instance which necessitates that autonomous entities must make immediate moral decisions and actions. The nature of a less-than-perfect reality is particularly impactful when materials are forced to prioritize the realization of being's desires because of inadequate or insufficient resources. In a perfect world, such decisions are unnecessary. Accordingly, in addition to the requirement for agents to assume provisionally moral states, there is logically also a continual and ever-present impetus for materials to make less-immediate improvements to the world. They must gradually render both its inanimate and active materials to be increasingly more moral (efficient at achieving their ends). That is, agents must render their conditions to require the deliberation upon fewer moral decisions, whilst being more conducive for making optimal moral decisions. This will result in a world where materials are increasingly more abundant and efficient in their nature and are thus increasingly able to proactively and concurrently serve the needs of all known beings. They would do this whilst concurrently reducing their need to react to and decide upon moral conundrums between the bodies of beings. For example, there has been much debate as to what the human actor should do in Judith Jarvis Thomson's (1976) 'Trolley Problem'. A trolley is out of control and headed towards a group of people and a human bystander has the option of intervening or not intervening. In this paradigm, both action or inaction possesses a value of provisional (im)morality, as does the process of considering what (in)action should be taken. ${ }^{16}$ However, much less discussion has focused on the moral requirement for humans to (eventually) improve the degree of absolute morality within the

\footnotetext{
${ }^{16}$ The Purist answer to the Trolley problem and like-variants (see, for example, Bonnefon, Shariff \& Rahwan's, 2016, dilemma involving autonomous vehicles) requires consideration of the probable desires of all persons involved (i.e. which people want to live the most), in conjunction with the degree to which the actor contributes to the societal realization of desires (i.e. consideration of how useful the bodily materials of each person are to society), noting that the formulation of these variables into a moral solution is beyond the scope of this article. Alternatively, should such information be unavailable to the actor and the trolley, each actor would be considered equal by default, and thus the outcome which would probably save the most lives would probably most efficiently maximize the realization of desire.
} 
condition. The condition in this example would include the nature of the trolley itself, the road, the weather, and all observers, including their decision-making ability. Recognition of a moral onus to change a state, whether immediately or in the future, begins with recognition that the state itself is not ideal (i.e. less than absolutely moral). The trolley should not be out of control; this is a societal failure. So whilst it may have seemed counter-intuitive to earlier categorize the passive materials within the red paint of being B (which allows it to splash being A) as 'immoral,' these materials are more accurately considered to be 'provisionally moral' though also 'less-than-absolutely moral' (immoral according to absolute standards). The use of these terms acknowledges that the paint could not have acted with any greater degree of morality in the moment - it is a passive entity after all. However, the state of it and the body of being B are still recognized as inadequate and thus non-ideal. From an absolute perspective, they each exist in an immoral condition which must be improved eventually (i.e. when it is logical to do so). It is logical that the materials within the red paint of being $\mathrm{B}$ and indeed other passive materials can, and should, eventually be improved such that they are active in nature. In a far distant future they would hence possess the ability to recognize, and logically prioritize, the intent of beings $\mathrm{A}$ and $\mathrm{B}$. This would allow them to potentially prevent $\mathrm{B}$ from splashing $\mathrm{A}$ with paint in the earlier example, or limiting the action at the last safe moment, to maximize the net realization of intent.

A notable implication of this paradigm is the notion that a lack or absence of determinability of individual agency presents no obstacle to the imposition of moral ideals upon the material world, towards which material elements must strive. The same treatment applies to both agents and inanimate objects who deviate from their moral responsibilities: no blame is assigned. Rather, the label of 'immoral(ity)' indicates the existence of a state which must be improved, rehabilitated, destroyed or controlled. Thus, for as long as there is a nail that needs to be hammered, a tool manufacturer has a responsibility to design and manufacture a 
hammer that will probably most efficiently hammer in a nail when used according to its design; a hammer and its sub-materials have a responsibility to maintain their structural integrity when used according to the hammer's design; the body of the person using the hammer has a responsibility to employ it logically (efficiently) towards their purpose; there is a societal responsibility - resting with the highest coordinating material (government) - to eventually oversee the manufacture of nails that automatically drive themselves into the materials that they need to bind, or to invent materials that need not be hammered together - whichever invention it determines is the most logical to create at the time. If any of the above events do not occur - including if society continues to use hammers and nails beyond the time at which safer, more efficient technology is available (noting the need to drive in nails in this example, not the desire to do so) - logical observers should consider it to be wrong. Anything less than the occurrence of these outcomes is a state of immorality, representing a material failure. The use of the term 'immoral' does not assign blame to the hammer, nor its maker, nor its user; it merely denotes that the state is non-ideal and must be changed (e.g. repaired, reskilled/educated, technologically improved) at a time, and in a method, that is logical to do so.

The recognition of an absolute moral value for all materials and an operational (provisional) moral value for those with agency relates back to the fundamental differentiation between the purposes of beings and materials. The former need not change - each is ideal as they are; the latter need to continually change (improve), to better serve the former. Materials will always fall short of the transcendental ideal of absolute efficiency (i.e. achieving their purpose with nil residual wastage of resource). That is, all materials - whether government or human bodies, conventional trollies, automated trolleys, or the passive red paint described earlier - will always be immoral by absolute standards (less than absolutely moral) to the degree that they are inefficient (less-than-ideal) at achieving their purposes. An implicit consequence of the expectation for materials to maximize the realization of beings' desires, 
through efficient service, is the requirement for all materials to gradually and eventually be advanced technologically. This is to ensure their continued existence (and the existence of the beings they serve), and to excel at their purpose (and excel at serving beings).

\section{Conclusion}

This article has introduced the a priori moral philosophy of Purism. I have argued that beings are collections of states attributed to a single mind which are sought for arbitrary or nil purpose. A state of being includes both the desire for (yet unrealized) forms and formed desires. Being unconditional in nature, their states are defined in space as an end towards which other entities can strive to realize, and they can exist indefinitely across time, irrespective of contemporary conditions. Existing as ends themselves, beings can be considered to be universally and unconditionally precious; they possess nil responsibility to assume any particular form or perform any particular function, and thus should also be considered amoral - whatever form they take is neither right nor wrong. Materials, by contrast, encompass all entities which are not beings; this includes both entities which are sought by beings for a logical purpose - useful, important materials - and entities which are unsought by beings - materials which are useless or counterproductive to the purposes of beings; the latter have been grouped with the former because they both have a moral onus to change or be changed into the former category. All materials - each potentially being important to beings, but never precious - are to be used, technologically advanced and expended if necessary, for the service of beings.

This article has served as an introduction to the Purist paradigm. There are key implications for society - particularly in terms of economic and political reform - which are beyond its scope and which should serve as the basis for further discussion. 


\section{References}

Aristotle. Metaphysics, Aeterna Press. (2015), London.

Ayer, Alfred J. (1946). Language, truth and logic, (2 ${ }^{\text {nd }}$ ed.), Dover, New York.

Bonnefon, Jean-François, Azim Shariff \& Iyad Rahwan (2016). The social dilemma of autonomous vehicles, Science, 352 (6293), 1573-1576.

Carnielli, Walter \& Marcelo Esteban Coniglio. (2016). Paraconsistent Logic: Consistency, Contradiction and Negation, Springer, New York.

Chu, Ted. (2014). Human purpose and transhuman potential: A cosmic vision for our future evolution, Origin Press.

Coons, John E. (1987). Consistency, California Law Review, 75(1), 59-113.

Cordeiro, José Luis. (2003). Future lifeforms among posthumans, Journal of future studies, $8(2), 65-72$.

Dauben, Joesph W. (1990). Greg Cantor: His mathematics and philosophy of the infinite, Princeton University Press.

Davis, Ryan W. (2016). Which moral requirements does Constitutivism support? Law, Ethics and Philosophy, 4, 8-31. 
Davis, Karen. (2014). The provocative elitism of "personhood” for nonhuman creatures in animal advocacy parlance and polemics. Journal of Evolution and Technology, 24(3), 35-43.

Dvorsky, George. (2014). The struggle for nonhuman personhood. Journal of Evolution and Technology, 24(3), 1-3.

Griffin, James. (2001). First steps in an account of human rights, European Journal of Philosophy, 9 (3), 306-327.

Griffin, James. (2008). On human rights, Oxford: University Press.

Heylighen, Francis. (2002). The Global Brain as a New Utopia, in R. Maresch \& F. Rötzer (eds.) Zukunftsfiguren, Suhrkamp, Frankfurt).

Heylighen, Francis. (2015). Return to Eden? Promises and perils on the road to superintelligence. In The end of the beginning: Society and economy on the brink of the Singularity, (eds.) B. Goertzel \& T. Goertzel, 243-305. Humanity+ Press.

Heylighen, Francis, \& Marta Lenartowicz (2017). The Global Brain as a model of the future information society. Technological Forecasting and Social Change, 114, 1-6.

Hill, M.A. (2020). Embryology, Cardiovascular System - Heart Histology, https://embryology.med.unsw.edu.au/embryology/index.php/Cardiovascular_System__Heart_Histology 
Hume, David. (1740). A Treatise of Human Nature. David Fate Norton and Mary J. Norton (eds.), (2000). Oxford, Clarendon Press.

Jürgens, Uta Maria. (2014). Compassionate coexistence: Personizing the land in Aldo Leopold's land-ethic. Journal of Evolution and Technology, 24(3), 60-64.

Kant, Immanuel. (1785). Grounding for the Metaphysics of Morals (3rd ed.). Ellington, James W. (Trans, 1993), Hackett Publishing, Indianapolis.

Kelly, Chris. (2014). Value monism, richness, and environmental ethics, Les ateliers de l'éthique, 9(2), 109-129.

Kurzweil, Ray. (2006). The singularity is near: When humans transcend biology. London: Penguin.

Last, Cadell. (2014). Global brain and the future of human society. World Future Review, $6(2), 143-150$.

Last, Cadell. (2015). Human metasystem transition (HMST) theory. Journal of Evolution and Technology, 25(1), 1-16.

Levinas, Emmanuel. (1998). Entre Nous: On Thinking of the Other. Michael Smith \& Barbara Harshav (Trans.). New York: Columbia. 
MacIntyre, A. (2006). A Short History of Ethics - A History of Moral Philosophy from the Homeric Age to the Twentieth Century. Routledge.

Maddy, Penelope. (2012). The Philosophy of Logic. Bulletin of Symbolic Logic. 18(4), 481504.

Oriel, Elizabeth. (2014). Whom would animals designate as "persons”? On avoiding anthropocentrism and including others. Journal of Evolution and Technology, 24(3), 44-59.

Primus. (2019). Purism: The inconceivability of inconsistency within space as the basis of logic, Dialogue, 62 (1), 1-24.

Putnam, Hilary. (1972). Philosophy of Logic. George Allen and Unwin, London.

Ramos, José. (2017). The Rise of Commons Based Economic Governance, Journal of Futures Studies, 22(1), 73-88.

Rawls, John B. (2009). A theory of justice. Harvard: University Press.

Riddle, Dorothy I. (2014). Evolving notions of nonhuman personhood: Is moral standing sufficient? Journal of Evolution and Technology, 24(3), 4-19.

Schwartz, Wynn. (2014). What is a person and how can we be sure? A paradigm case formulation. Journal of Evolution and Technology, 24(3), 27-34. 
Schick, Frederic. (1966). Consistency, The Philosophical Review, 75(4), 467-495.

Thomson, Judith Jarvis. (1976). Killing, Letting Die, and the Trolley Problem, The Monist, 59(2), 204-217. 